\title{
Nasal packing: when a routine practice becomes a life-threatening emergency
}

Eva Novoa ${ }^{1}$ and Helge Junge ${ }^{1}$

${ }^{1}$ Kantonsspital Graubunden

June 25, 2020

\begin{abstract}
Nasal packing constitutes a common step in nasal procedures. A correct fixation is of uttermost importance to avoid posterior dislocation and aspiration. This case report highlights the risk of acute airway situations involving nasal packs and discuses common errors that should be avoided to prevent this life-threatening complication.
\end{abstract}

\section{Hosted file}

Netcell_aspiration_CCR.doc available at https://authorea.com/users/336677/articles/462329nasal-packing-when-a-routine-practice-becomes-a-life-threatening-emergency

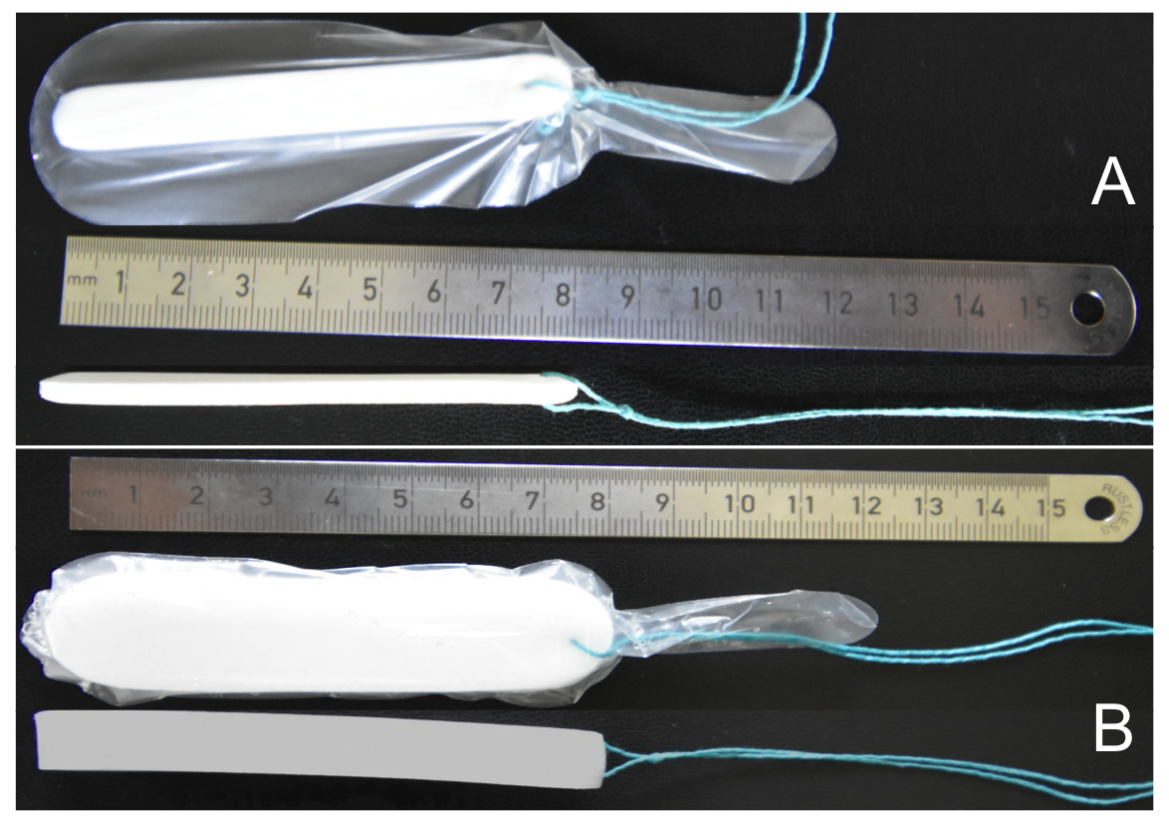




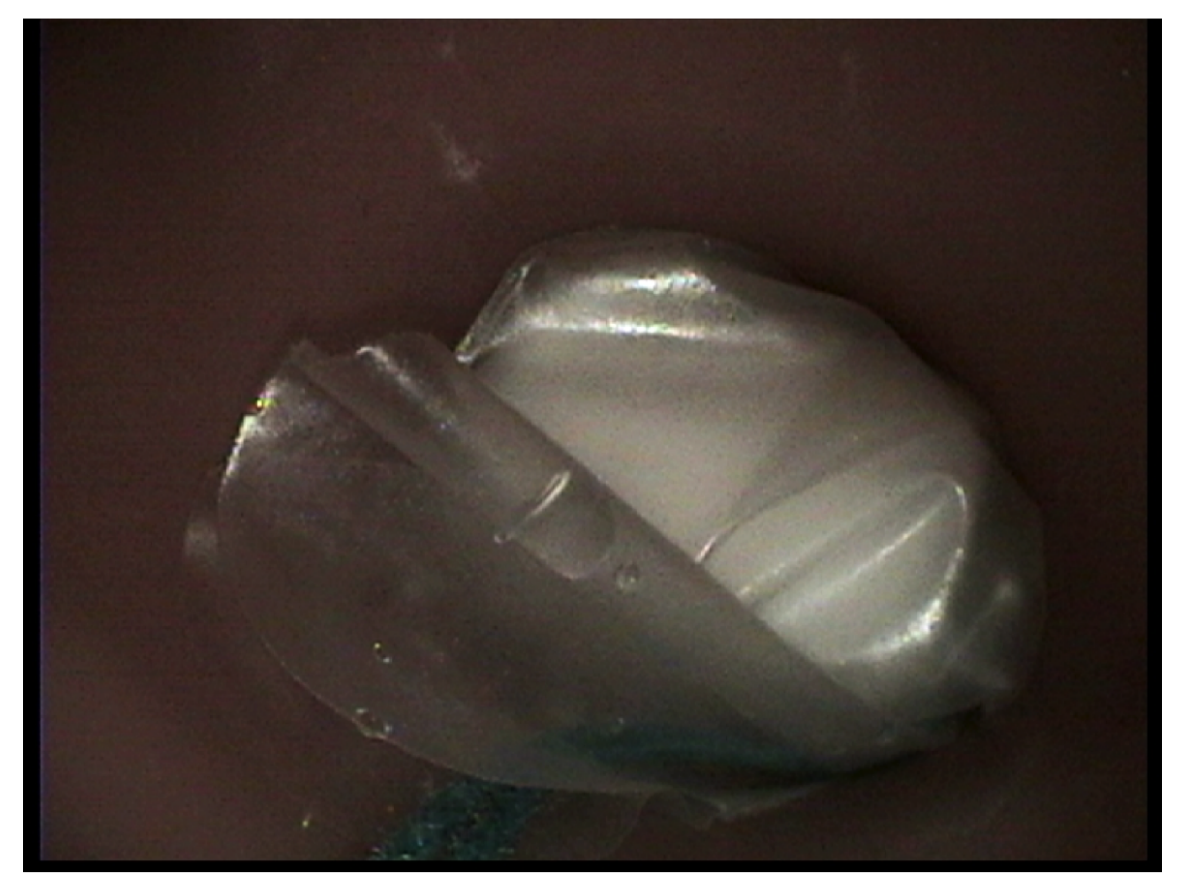

